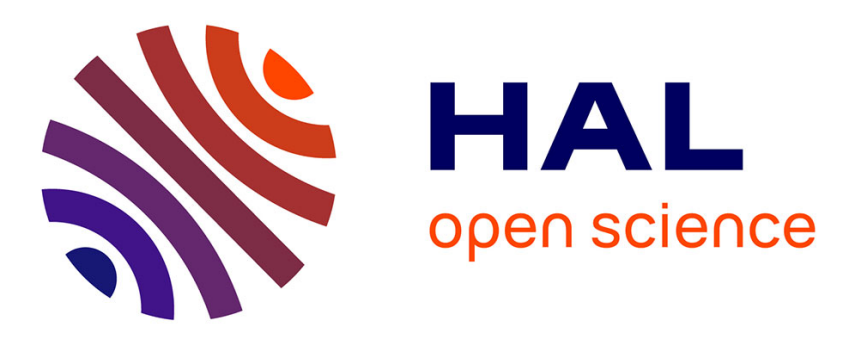

\title{
Induction machine faults detection based on a constant false alarm rate detector
}

\author{
Youness Trachi, Elhoussin Elbouchikhi, Vincent V. Choqueuse, Tianzhen \\ Wang, Mohamed Benbouzid
}

\section{- To cite this version:}

Youness Trachi, Elhoussin Elbouchikhi, Vincent V. Choqueuse, Tianzhen Wang, Mohamed Benbouzid. Induction machine faults detection based on a constant false alarm rate detector. IECON, Oct 2016, Florence, Italy. pp.6359 - 6363, 10.1109/IECON.2016.7793928 . hal-01449096

\section{HAL Id: hal-01449096 https://hal.science/hal-01449096}

Submitted on 30 Jan 2017

HAL is a multi-disciplinary open access archive for the deposit and dissemination of scientific research documents, whether they are published or not. The documents may come from teaching and research institutions in France or abroad, or from public or private research centers.
L'archive ouverte pluridisciplinaire HAL, est destinée au dépôt et à la diffusion de documents scientifiques de niveau recherche, publiés ou non, émanant des établissements d'enseignement et de recherche français ou étrangers, des laboratoires publics ou privés. 


\title{
Induction Machines Fault Detection based on Constant False Alarm Rate Detector
}

\author{
Youness Trachi ${ }^{1}$, Elhoussin Elbouchikhi ${ }^{2}$, Vincent Choqueuse ${ }^{1}$, Tianzhen Wang ${ }^{3}$, and Mohamed Benbouzid ${ }^{1,3}$ \\ ${ }^{1}$ University of Brest, FRE CNRS 3744 IRDL, Brest, France. \\ ${ }^{2}$ ISEN Brest, FRE CNRS 3744 IRDL, Brest, France. \\ 3 Shanghai Maritime University, 201306 Shanghai, China. \\ Email: Youness.Trachi@univ-brest.fr, elbouchikhi@isen-bretagne.fr, \\ Vincent.Choqueuse@univ-brest.fr, tzwang@shmtu.edu.cn, \\ and Mohamed.Benbouzid@univ-brest.fr
}

\begin{abstract}
This paper proposes a new method for fault detection in three-phase induction machines based on the stator current measurements. The proposed detection method is based on the hypothesis testing. Specifically, this paper investigates a binary detection problem: the machine is healthy or faulty. The Generalized Likelihood Ratio Test (GLRT) is used to address this statistical detection problem with unknown signal and noise parameters. This proposed detector is a Constant False Alarm Rate (CFAR) detector. The decision is obtained according to a threshold, which is set to reach a desired false alarm probability. To implement this detector, four estimations based one the Maximum-Likelihood-Estimator (MLE) are required: model order, frequency, phase and amplitude estimations. Frequencies are estimated by Total Least Squares-Estimation of Signal Parameters via Rotational Invariance Techniques (TLS-ESPRIT). Two types of faults are considered: bearing and broken rotor bars faults. Experimental tests clearly show the effectiveness of the proposed detector]
\end{abstract}

Index Terms-Induction machine, bearing faults, broken rotor bars, MLE, subspace techniques, TLS-ESPRIT, CFAR detector, GLRT criterion.

\section{INTRODUCTION}

Nowadays, the condition monitoring has become a necessity in industrial applications to avoid unplanned downtime and ensure electrical power supply quality. Consequently, fault detection and diagnosis of electrical machines has become an important research topic. It has been demonstrated that several faults can affect induction machines. The main induction machine fault types studied in the literature are generally classified into electrical and mechanical faults $[1]-[4]$. The most common electrical faults that could appear are open or short circuit in machine windings (mainly due to winding insulation failure), wrong connection of windings, high resistance contact to conductor, and wrong or unstable ground [5]. Besides, mechanical faults include: broken rotor bars, cracked end-rings, bent shaft, bolt loosening, bearing failure, gearbox failure, and air-gap irregularity [5].

The challenge then is to detect these faults using stator currents processing. Several estimation techniques have been proposed to analysis and detect these faults [4], [6]-[16]. To

This work was supported in parts by the National Natural Science Foundation of Shanghai (NO.16ZR1414300). estimate the stator current power spectral density, two main estimation techniques have been investigated: the nonparametric and the parametric techniques. It has been demonstrated that parametric techniques give better performances than nonparametric techniques for short data measurements. The parametric techniques are widely based on statistical models to estimate model parameters from the available signal data. In the literature, several parametric techniques have been proposed for fault detection, which include the MLE and the subspace techniques [4], [6]-[13], [15], [16].

To detect faults in induction machines based on stator current measurements, the existing techniques can be categorized into two subclasses: artificial intelligence and detection theory. The artificial intelligence techniques proposed in the literature include artificial neural networks (ANNs) [17]-[21], support vector machine (SVM) technique [22], [23], Fuzzy Logic [24], [25], and combined techniques [26]. Unfortunately, these artificial intelligence techniques require massive computational resources. Furthermore, their performances depend on the feature selection used to process the stator current. The detection theory allows to make an optimal decision in order to identify which hypothesis is true. The popular criteria defining the detection procedure with unknown signal and noise parameters are the Bayesian and the Neyman-Pearson approaches. The Bayesian approach is a detector to composite hypothesis testing. The unknown parameters are considered as realizations of random variables and are assigned a prior Probability Density Function (PDF) [27]. Unfortunately, this approach requires multidimensional integration with a dimension equal to the unknown parameter dimension. The NeymanPearson approach involves a maximization of the probability of detection $P_{D}$ for a given probability of false alarm $P_{F a}$ [28]. It is based on the likelihood ratio test of the PDFs under a binary hypothesis. The Threshold of this test is chosen from the false alarm constraint. When the likelihood ratio depends on unknown parameters, these parameters are replaced by their estimated ones using the MLE. This solution is known as the Generalized Likelihood Ratio Test.

This paper considers the problem of induction machines faults detection. This problem is formulated as a binary hypothesis that considers two cases: the induction machine is healthy or faulty. This statistical problem can be considered as a detection of signals in noise with unknown signal and 
noise parameters. In this context, the Generalized Likelihood Ration Test (GLRT) is used to make a decision according to a threshold. The GLRT criterion combines two signal processing theories: estimation and detection. The unknown parameters of the stator current model are replaced by their estimated ones using MLE. Four estimations are required: model order, frequency, phase and amplitude estimations. The model order estimation is obtained by using the criterion given in [29] that associates the order-selection rules with the MLE. To avoid the MLE drawbacks for frequency estimation such as computational complexity inherent to multidimensional optimization, the TLS-ESPRIT is proposed for frequency estimation. Then, amplitudes and phases are estimated based on the Least-Squares Estimator (LSE). Finally, the GLRT is used for decision making.

\section{Stator CurRent Parameters Estimation}

In this section, a stator current model under the considered faults is presented. The model parameters are estimated on MLE and TLS-ESPRIT associated with Bayesian Information Criterion (BIC) model selection rule.

\section{A. Stator Current Model}

Fault detection using advanced statistical techniques needs to select a good model. The induction machine stator current in presence of faults can be described by the following model [11]

$$
x[n]=\sum_{k=0}^{L-1} a_{k} \cos \left(2 \pi f_{k} \frac{n}{F_{s}}+\phi_{k}\right)+b[n]
$$

where $x[n]$ denotes the stator current samples, $b[n] \sim$ $\mathcal{N}_{c}\left(0, \sigma^{2}\right)$ is a white Gaussian noise, $L$ represents the model order, $F_{s}$ is the sampling frequency, $a_{k}, f_{k}$, and $\phi_{k}$ are amplitude, frequency, and initial phase of the $k^{t h}$ component, respectively.

At time $n=0,1,2,3, \ldots, N-1$, the observed stator current vector $\mathbf{x}$, defined as $\mathbf{x}=\left[\begin{array}{lll}x(0) & \ldots & x(N-1)\end{array}\right]^{T}$, can be expressed as

$$
\mathbf{x}=\mathbf{H}(\boldsymbol{\Omega}) \boldsymbol{\theta}+\mathbf{b}
$$

where

$$
\begin{aligned}
& -\boldsymbol{\theta}=[\Re e(\mathbf{v})-\Im m(\mathbf{v})]^{T} \text { is a } 2 L \times 1 \\
& -\mathbf{H}(\boldsymbol{\Omega})=[\Re e(\mathbf{B}(\boldsymbol{\Omega})) \quad \Im m(\mathbf{B}(\boldsymbol{\Omega}))] \text { is a }
\end{aligned}
$$

It has been demonstrated that faults introduce additional frequencies in the stator current spectrum, in the form of sidebands close to the fundamental frequency and other space harmonics present in the stator current. These additional frequencies called faulty frequencies can be described by

$$
f_{f}=f_{s} \pm k f_{c},
$$

where $f_{s}$ is the supply fundamental frequency, $f_{c}$ is the fault characteristic frequency, and $k \in \mathbb{N}^{*}$.

\section{B. Parameters Estimation}

The model parameters estimates can be obtained using the Nonlinear Least Squares Estimator (NLSE). This estimator corresponds to the MLE, when the noise is assumed to be white Gaussian. In parametric estimation context, Minimum Variance Unbiased (MVU) estimator is often difficult to find, in which case we can resort to the asymptotically suboptimal, but tractable estimator such as MLE. This estimator is asymptotically unbiased and efficient [30]. The MLE is found by maximizing $\ln p(\mathbf{x}, \boldsymbol{\Omega}, \boldsymbol{\theta})$

$$
\{\widehat{\boldsymbol{\Omega}}, \widehat{\boldsymbol{\theta}}\}=\operatorname{argmax} \ln p(\mathbf{x}, \boldsymbol{\Omega}, \boldsymbol{\theta})
$$

where $p(\mathbf{x}, \boldsymbol{\Omega}, \boldsymbol{\theta})$ is the PDF of the $\mathbf{x}$ that is given by

$p(\mathbf{x}, \boldsymbol{\Omega}, \boldsymbol{\theta})=\frac{1}{\left(2 \pi \sigma^{2}\right)^{\frac{N}{2}}} \times \exp \left(\frac{-1}{2 \sigma^{2}}(\mathbf{x}-\mathbf{H}(\boldsymbol{\Omega}) \boldsymbol{\theta})^{T}(\mathbf{x}-\mathbf{H}(\boldsymbol{\Omega}) \boldsymbol{\theta})\right)$

The maximization in (4) is equivalent to the minimization of the following cost function

$$
J(\mathbf{x}, \boldsymbol{\Omega}, \boldsymbol{\theta})=(\mathbf{x}-\mathbf{H}(\boldsymbol{\Omega}) \boldsymbol{\theta})^{T}(\mathbf{x}-\mathbf{H}(\boldsymbol{\Omega}) \boldsymbol{\theta})
$$

This estimation problem can be divided into three estimation problems: frequency, phase and amplitude estimations.

To estimate frequencies, the MLE requires the maximization of a multidimensional and multimodal cost function. Fortunately, it is possible to approach the performances of MLE by using subspace techniques. The subspace techniques are based on the eigendecomposition of the covariance matrix. This matrix can be estimated from the observed stator current vector $\mathrm{x}$ by

$$
\widehat{\mathbf{R}}_{x}=\frac{1}{N} \sum_{n=0}^{N-1} \mathbf{x x}^{H}
$$

The covariance matrix can be written in terms of its eigenvalues decomposition by

$$
\mathbf{R}_{x}=\left[\begin{array}{ll}
\mathbf{S} & \mathbf{G}
\end{array}\right]\left[\begin{array}{cc}
\boldsymbol{\Lambda}_{s} & 0 \\
0 & \boldsymbol{\Lambda}_{g}
\end{array}\right]\left[\begin{array}{ll}
\mathbf{S} & \mathbf{G}
\end{array}\right]^{H}
$$

where $\boldsymbol{\Lambda}_{s}$ and $\boldsymbol{\Lambda}_{g}$ are diagonal matrices containing eigenvalues of signal and noise subspaces arranged in descending order, respectively ( $\mathbf{S}$ and $\mathbf{G}$ are the associated orthonormal eigenvectors, respectively). This decomposition allows to identify two subspaces: signal subspace and noise subspace [31]. There are two main categories of subspace techniques: MUSIC (MUltiple SIgnal Classification) techniques based on the noise subspace and ESPRIT techniques based on the signal subspace. It is known that ESPRIT out perform MUSIC in terms of statistical performance [32]. Therefore, ESPRIT techniques are preferred over the MUSIC techniques for frequency estimation [32]. 
The ESPRIT techniques include two extensions: Least-Squares (LS) ESPRIT and Total Least-Squares (TLS) ESPRIT. The TLS-ESPRIT involves slightly more computations, it is generally preferred over the LS-ESPRIT thanks to its performance for frequency estimation [31]. Let $\mathbf{S}_{1}=\left[\begin{array}{ll}\mathbf{I}_{N-1} & 0\end{array}\right] \mathbf{S}$ and $\mathbf{S}_{2}=\left[\begin{array}{cc}0 & \mathbf{I}_{N-1}\end{array}\right] \mathbf{S}$ be unstaggered and staggered signal subspaces, respectively. The key element of TLS-ESPRIT technique for frequency estimation is the Singular Value Decomposition (SVD) of $\left[\begin{array}{ll}\mathbf{S}_{1} & \mathbf{S}_{2}\end{array}\right]=\mathbf{L} \boldsymbol{\Sigma} \mathbf{V}^{H}$, where $\mathbf{L}$ is a matrix of left singular vectors, $\boldsymbol{\Sigma}$ is a matrix consisting of singular values on the main diagonal ordered in descending magnitude, and $\mathbf{V}$ is a matrix of right singular vectors. The matrix $\mathbf{V}$ is an $(4 L \times 4 L)$ unitary matrix, which can be partitioned into $(2 L \times 2 L)$ quadrants according to

$$
\mathbf{V}=\left[\begin{array}{ll}
\mathbf{V}_{11} & \mathbf{V}_{12} \\
\mathbf{V}_{21} & \mathbf{V}_{22}
\end{array}\right]
$$

The frequencies are estimated by using eigenvalues of $\boldsymbol{\Phi}_{T L S}$ that is given by

$$
\boldsymbol{\Phi}_{T L S}=-\mathbf{V}_{12} \mathbf{V}_{22}^{-1} \text {. }
$$

The eigenvalues $\varphi_{k}$ of $\widehat{\boldsymbol{\Phi}}_{T L S}$ allow determining $2 L$ frequencies according to

$$
\widehat{f}_{k}=\frac{\arg \left(\varphi_{k}\right)}{2 \pi} \times F_{s} .
$$

Thereafter, we keep only positive frequencies.

Phases and amplitudes are obtained by using the LSE

$$
\widehat{\boldsymbol{\theta}}=\left(\mathbf{H}^{T}(\widehat{\boldsymbol{\Omega}}) \mathbf{H}(\widehat{\boldsymbol{\Omega}})\right)^{-1} \mathbf{H}^{T}(\widehat{\boldsymbol{\Omega}}) \mathbf{x}
$$

The previous estimations assume that the model order is known. When the model order is unknown, its value is obtained by minimizing the BIC given in [29]. This estimator is defined by

$$
\widehat{L}=\arg \min _{L} N \ln \left(\widehat{\sigma}_{L}^{2}\right)+n \ln (N)
$$

where $N$ is the number of samples, $n=3 L+1$, and $\widehat{\sigma}_{L}^{2}$ denotes the noise variance given by

$$
\widehat{\sigma}_{L}^{2}=\frac{1}{N} \sum_{n=0}^{N-1}\left|x[n]-\sum_{k=0}^{L-1} \widehat{a}_{k} \cos \left(2 \pi \widehat{f}_{k} \frac{n}{F_{s}}+\widehat{\phi}_{k}\right)\right|^{2} .
$$

where $\widehat{a}_{k}=|\widehat{\mathbf{v}}|$ and $\widehat{f}_{k}=\arg (\widehat{\mathbf{v}})$.

\section{Generalized LiKelihood RATIO TEST}

In this section, a GLRT criterion is proposed to detect faults in induction machines.

\section{A. Hypothesis Testing}

We consider the problem of detecting the faults in induction machines. Therefore, one of two hypothesis can be assumed true:

$\mathcal{H}_{0}$ : The machine is healthy.

$\mathcal{H}_{1}$ : The machine is faulty.
In this case, $\mathcal{H}_{0}$ is referred to as the null hypothesis and $\mathcal{H}_{1}$ as the alternative hypothesis. These hypotheses are associated with unknown parameters. This problem is known as a binary hypothesis test since we must choose between two hypothesis [28]. The objective is to decide if the amplitudes of faulty frequencies are null $\mathcal{H}_{0}$ or not null $\mathcal{H}_{1}$. This problem can be described mathematically in terms of a hypothesis test between the following binary hypothesis:

$$
\begin{array}{lll}
\mathcal{H}_{0}: a_{k}^{\prime}=0 & \forall k \neq 0, & \sigma^{2}>0 \\
\mathcal{H}_{1}: a_{k}^{\prime} \neq 0 & \forall k \neq 0, & \sigma^{2}>0
\end{array}
$$

where the amplitudes $a_{k}^{\prime}$ refer to amplitudes of faulty frequencies. These hypothesis can be written as a following matrix formulation

$$
\begin{array}{ll}
\mathcal{H}_{0}: \mathbf{A} \boldsymbol{\theta}=0, & \sigma^{2}>0 \\
\mathcal{H}_{1}: \mathbf{A} \boldsymbol{\theta} \neq 0, & \sigma^{2}>0
\end{array}
$$

where $\mathbf{A}$ is an $(r \times p)$ matrix $(r \leq p=2 L)$ of rank $r$. This matrix is an $(p \times p)$ identity matrix from which rows corresponding to the fundamental frequency and all harmonic components are removed.

\section{B. GLRT Detector}

To decide which hypothesis is true, the GLRT is proposed as a detector. The GLRT is based on the likelihood ratio test of the PDFs under the binary hypothesis. The unknown parameters are replaced by their estimates based on the MLE. The GLRT for the considered hypothesis testing is to decide $\mathcal{H}_{1}$ if

$\mathcal{T}(\mathbf{x})=\frac{N-p}{r} \frac{\left(\mathbf{A} \widehat{\boldsymbol{\theta}}_{1}\right)^{T}\left[\mathbf{A}\left(\mathbf{H}^{T} \mathbf{H}\right)^{-1} \mathbf{A}^{T}\right]^{-1}\left(\mathbf{A} \widehat{\boldsymbol{\theta}}_{1}\right)}{\mathbf{x}^{T}\left(\mathbf{I}-\mathbf{H}\left(\mathbf{H}^{T} \mathbf{H}\right)^{-1} \mathbf{H}^{T}\right) \mathbf{x}}>\gamma^{\prime}$

where $\widehat{\boldsymbol{\theta}}_{1}$ is the MLE of $\boldsymbol{\theta}$ under $\mathcal{H}_{1}$ or the unrestricted MLE and $\mathbf{H}$ refers to the matrix $\mathbf{H}(\boldsymbol{\Omega})$. Based on the value of $\mathcal{T}(\mathbf{x})$, we make a decision. The threshold is found from the false alarm constraint [28].

The detection performance of a system is measured mainly by two factors: Probability of false alarm $P_{F a}$ and Probability of detection $P_{D}$. This performance is given by

$$
\begin{aligned}
& P_{F a}=Q_{F_{r, N-p}}\left(\gamma^{\prime}\right) \\
& P_{D}=Q_{F_{r, N-p}^{\prime}(\lambda)}\left(\gamma^{\prime}\right)
\end{aligned}
$$

where $Q_{P D F}(x)$ is the complementary commutative distribution function for a PDF random variable $x, F_{r, N-p}$ denotes an $F$ distribution with $r$ numerator degrees of freedom and $N-p$ denominator degrees of freedom, and $F_{r, N-p}^{\prime}(\lambda)$ denotes a noncentral $F$ distribution with $r$ numerator degrees of freedom, $N-p$ denominator degrees of freedom and noncentrality parameters $\lambda$. The noncentrality parameter is given by

$$
\lambda=\frac{\left(\mathbf{A} \widehat{\boldsymbol{\theta}}_{1}\right)^{T}\left[\mathbf{A}\left(\mathbf{H}^{T} \mathbf{H}\right)^{-1} \mathbf{A}^{T}\right]^{-1}\left(\mathbf{A} \widehat{\boldsymbol{\theta}}_{1}\right)}{\sigma^{2}}
$$

where $\boldsymbol{\theta}_{1}$ is the true value of $\boldsymbol{\theta}$ under $\mathcal{H}_{1}$. 
TABLE I. BEARING FAULT SEVERITY VERSUS HOLE DIAMETER.

\begin{tabular}{|c||c|c|c|c|c|}
\hline $\begin{array}{c}\text { Fault } \\
\text { severity }\end{array}$ & 1 & 2 & 3 & 4 & 5 \\
\hline $\begin{array}{c}\text { Bearing hole } \\
\text { diameter (inches) }\end{array}$ & 0.007 & 0.014 & 0.02 & 0.03 & 0.04 \\
\hline
\end{tabular}

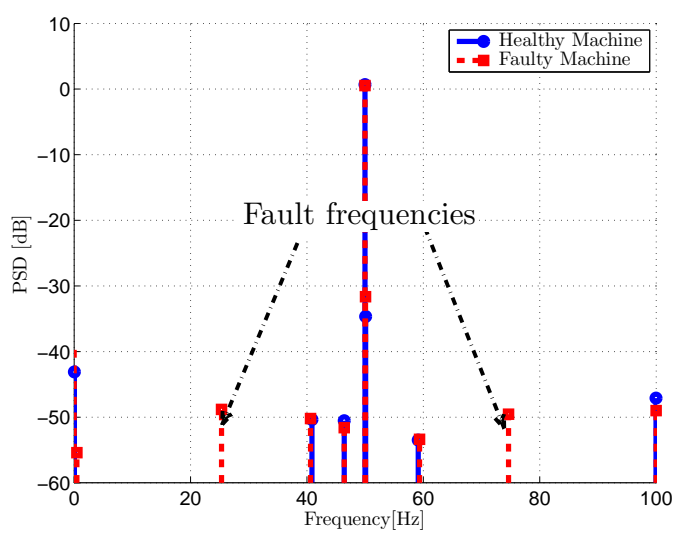

Fig. 2. Stator current spectrum based on TLS-ESPRIT for healthy and faulty induction machines with bearing faults (severity 4).

\section{EXPERIMENTAL TESTS}

The proposed approach for induction machine faults detection is tested on experimental data for broken rotor bars and bearing faults detection and diagnosis.

\section{A. Experimental Setup Description}

Two induction machines have been studied. The first induction machine with bearing faults. In this case, the machine under test is a $230 / 400 \mathrm{~V}, 0.75 \mathrm{~kW}$, three phases induction machine with pole pairs numbers equal to $p=1$ and 2780 rpm rated speed. The induction machine has two 6204-2 ZR type bearings (single row and deep groove ball bearings) with the following parameters: outside diameter is $47 \mathrm{~mm}$, inside diameter is $20 \mathrm{~mm}$, and pitch diameter $\mathrm{D}$ is $31,85 \mathrm{~mm}$. Bearings have 8 balls with an approximate diameter $d$ of 12 $\mathrm{mm}$ and a contact angle of 0 . Bearing faults are obtained by drilling holes of several diameters in the inner raceway (faults ranging from 0.007 inches $(0.178 \mathrm{~mm})$ in diameter to 0.040 inches $(1.016 \mathrm{~mm})$ as it can be seen in Table II). The stator currents acquisition is performed by a 24 bits acquisition card with $10 \mathrm{kHz}$ sampling frequency. The second induction machine with broken rotor bars. The machine under test is a $230 / 400 \mathrm{~V}, 5-\mathrm{kW}$, three phases induction machine. These faults are obtained by drilling the bar of the squirrel cage. The stator currents acquisition is performed by a 24 bits acquisition card with $20 \mathrm{kHz}$ sampling frequency. All the experiments were done in steady state conditions. The machines under study are fed by a PWM inverter with a fundamental frequency equals to $f_{s}=50 \mathrm{~Hz}$. The experimental setup is given by Fig. 1

\section{B. Experimental Results}

1) Bearing Faults Detection: Figure 2, shows the stator current spectrum using TLS-ESPRIT technique for healthy and faulty induction machines with bearing faults. In this figure,

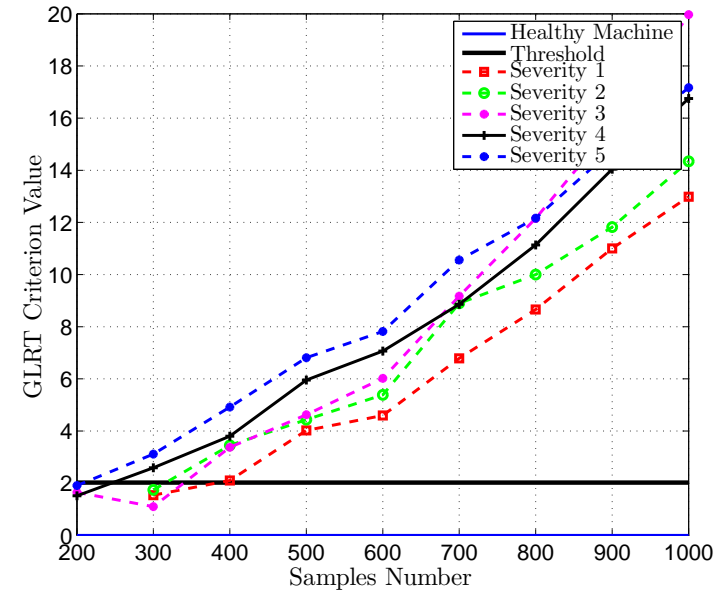

Fig. 3. GLRT criterion versus $N$ for healthy and faulty induction machines with different severities of bearing faults.

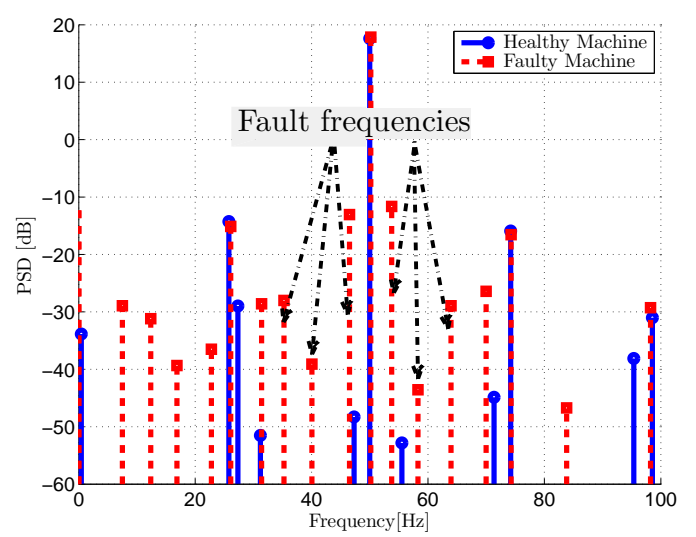

Fig. 4. Stator current spectrum based on TLS-ESPRIT for healthy and faulty induction machines with 3 broken rotor bars.

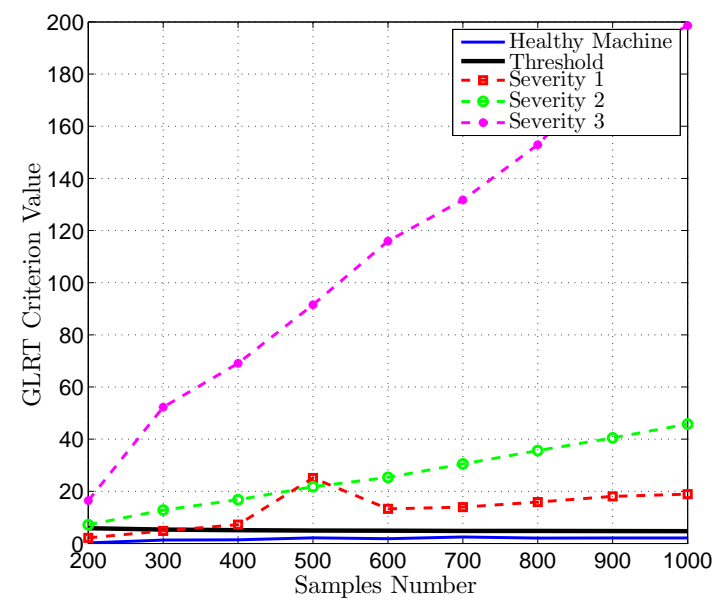

Fig. 5. GLRT criterion versus $N$ for healthy and faulty induction machines with different broken rotor bars severities.

additional frequency components appear in the stator current spectrum for faulty machines. These frequencies are the bearing faults signatures. Figure 3 gives the GLRT evolution with respect to samples number for healthy and faulty machines 


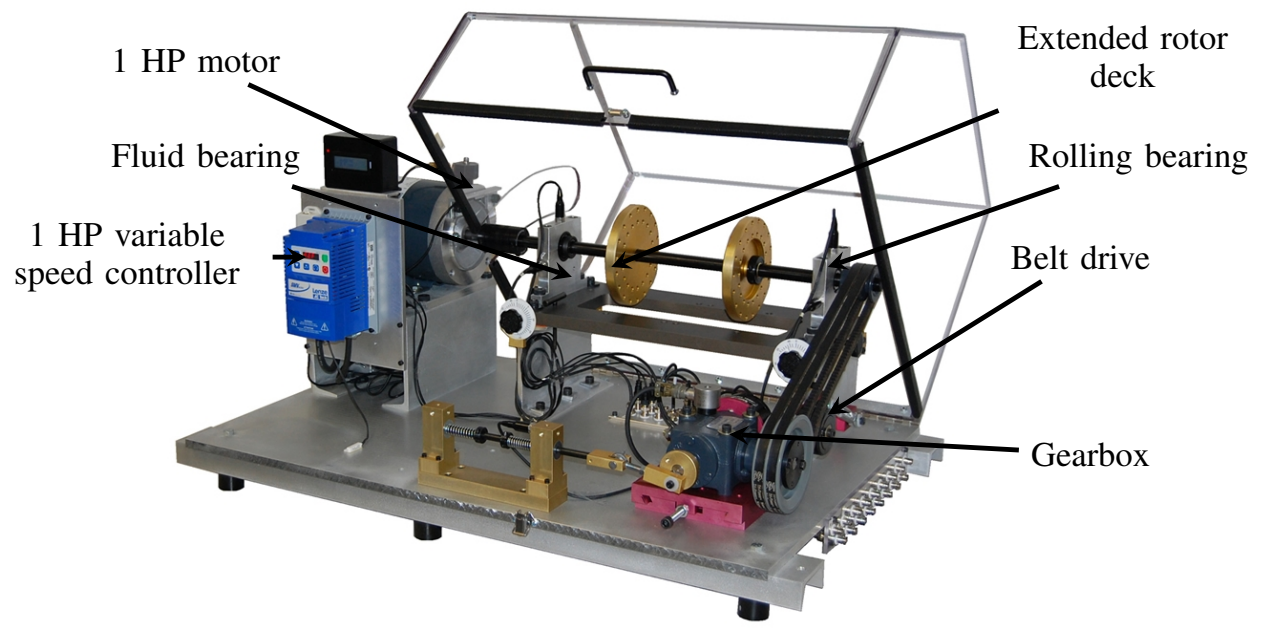

Fig. 1. Machinery fault simulator.

with different considered bearing faults severities. This figure shows the detection ability of the proposed detector for $N$ greater than 500 samples.

2) Broken Rotor Bars Faults Detection: Figure 4 shows the stator current spectrum using TLS-ESPRIT technique for healthy and faulty induction machines with 3 broken rotor bars. Figure 5 depicts the evolution of the proposed detector with respect to sample numbers for healthy and faulty machines with 1,2 , and 3 broken rotor bars. According to this figure, for $N$ greater than 400 samples, the proposed approach results are reliable.

\section{CONCLUSION}

This paper has proposed a new fault detection approach based on the GLRT criterion. The GLRT is used for decision making. The decision is based on the threshold which is computed using the fixed probability of false alarm. The decision is obtained by comparison between the GLRT value and the threshold. To compute the GLRT value, a parameters estimation is needed. Thus, four estimations have been presented: model order, frequency, phase, and amplitude estimations. Experimental results have been presented and have confirmed the detection effectiveness of the proposed detector.

\section{REFERENCES}

[1] M. Blödt, D. Bonacci, J. Regnier, M. Chabert, and J. Faucher, "Online monitoring of mechanical faults in variable-speed induction motor drives using the wigner distribution," IEEE Transactions on Industrial Electronics, vol. 55, no. 2, pp. 522-533, 2008.

[2] P. Zhang, Y. Du, T. G. Habetler, and B. Lu, "A survey of condition monitoring and protection methods for medium-voltage induction motors," IEEE Transactions on Industry Applications, vol. 47, no. 1, pp. 34-46, January/ February 2011.

[3] E. Elbouchikhi, V. Choqueuse, Y. Trachi, and M. Benbouzid, "Induction machine bearing faults detection based on hilbert-huang transform," in Proceedings of the 2015 IEEE ISIE, (Rio de Janeiro, Brazil), pp. 843848, June 2015.

[4] E. Elbouchikhi, V. Choqueuse, and M. Benbouzid, "Induction machine bearing faults detection based on a multi-dimensional music algorithm and maximum likelihood estimation," ISA transactions, 2016, http://dx.doi.org/10.1016/j.isatra.2016.03.007.
[5] H. A. Toliyat, S. Nandi, S. Choi, and H. Meshgin-Kelk, Electric Machines: Modeling, Condition Monitoring, and Fault Diagnosis. CRC Press, October 2012.

[6] M. E. H. Benbouzid, M. Vieira, and C. Theys, "Induction motors' faults detection and localization using stator current advanced signal processing techniques," IEEE Transactions on Power Electronics, vol. 14, no. 1, pp. 14-22, January 1999.

[7] A. Garcia-Perez, R. de Jesus Romero-Troncoso, E. Cabal-Yepez, and R. A. Osornio-Rios, "The application of high-resolution spectral analysis for identifying multiple combined faults in induction motors," IEEE Transactions on Industrial Electronics, vol. 58, no. 5, pp. 2002-2010, May 2011.

[8] B. Xu, L. Sun, L. Xu, and G. Xu, "An ESPRIT-SAA-based detection method for broken rotor bar fault in induction motors," IEEE Transactions on Energy Conversion, vol. 27, no. 3, pp. 654-660, September 2012.

[9] B. Xu, L. Sun, L. Xu, and G. Xu, "Improvement of the Hilbert method via ESPRIT for detecting rotor fault in induction motors at low slip," IEEE Transactions on Energy Conversion, vol. 28, no. 1, pp. 225-233, March 2013.

[10] Y.-H. Kim, Y.-W. Youn, D.-H. Hwang, J.-H. Sun, and D.-S. Kang, "High-resolution parameter estimation method to identify broken rotor bar faults in induction motors," IEEE Transactions on Industrial Electronics, vol. 60, no. 9, pp. 4103-4117, September 2013.

[11] E. Elbouchikhi, V. Choqueuse, and M. E. H. Benbouzid, "A parametric spectral estimator for faults detection in induction machines," in Proceedings of the 2013 IEEE IECON, (Montreal, Canada), pp. 7358-7363, November 2013

[12] E. Elbouchikhi, V. Choqueuse, and M. E. H. Benbouzid, "Induction machine faults detection using stator current parametric spectral estimation," Mechanical Systems and Signal Processing, vol. 52, pp. 447-464, June 2014

[13] Y. Trachi, E. Elbouchikhi, V. Choqueuse, and M. E. H. Benbouzid, "Stator current analysis by subspace methods for fault detection in induction machines," in Proceedings of the 2015 IEEE IECON, (Yokohama, Japon), pp. 1-6, November 2015.

[14] E. Elbouchikhi, V. Choqueuse, and M. Benbouzid, "Induction machine diagnosis using stator current advanced signal processing," International Journal on Energy Conversion, vol. 3, no. 3, pp. 76-87, 2015.

[15] M. Sahraoui, A. J. M. Cardoso, and A. Ghoggal, "The use of a modified prony method to track the broken rotor bar characteristic frequencies and amplitudes in three-phase induction motors," IEEE Transactions on Industry Applications, vol. 51, no. 3, pp. 2136-2147, May/June 2015.

[16] Y. Trachi, E. Elbouchikhi, V. Choqueuse, and M. E. H. Benbouzid, "Induction machines fault detection based on subspace spectral estimation," IEEE Transactions on Industrial Electronics, to appear in 2016. 
[17] K. Kim and A. G. Parlos, "Induction motor fault diagnosis based on neuropredictors and wavelet signal processing," IEEE/ASME Transactions on Mechatronics, vol. 7, no. 2, pp. 201-219, June 2002.

[18] M. D. Prieto, G. Cirrincione, A. G. Espinosa, J. A. Ortega, and H. Henao, "Bearing fault detection by a novel condition-monitoring scheme based on statistical-time features and neural networks," IEEE Transactions on Industrial Electronics, vol. 60, no. 8, pp. 3398-3407, August 2013.

[19] H. C. Cho, J. Knowles, M. S. Fadali, and K. S. Lee, "Fault detection and isolation of induction motors using recurrent neural networks and dynamic bayesian modeling," IEEE Transactions on Control Systems Technology, vol. 18, no. 2, pp. 430-437, 2010.

[20] H. Su and K. T. Chong, "Induction machine condition monitoring using neural network modeling," IEEE Transactions on Industrial Electronics, vol. 54, no. 1, pp. 241-249, 2007.

[21] V. N. Ghate and S. V. Dudul, "Cascade neural-network-based fault classifier for three-phase induction motor," IEEE Transactions on Industrial Electronics, vol. 58, no. 5, pp. 1555-1563, May 2011.

[22] J. Seshadrinath, B. Singh, and B. K. Panigrahi, "Incipient turn fault detection and condition monitoring of induction machine using analytical wavelet transform," IEEE Transactions on Industry Applications, vol. 50, no. 3, pp. 2235-2242, May/June 2014.

[23] H. Keskes and A. Braham, "Recursive undecimated wavelet packet transform and dag svm for induction motor diagnosis," IEEE Transactions on Industrial Informatics, vol. 11, no. 5, pp. 1059-1066, October 2015 .

[24] F. Zidani, M. E. H. Benbouzid, D. Diallo, and M. S. Naït-Saïd, "Induction motor stator faults diagnosis by a current concordia pattern-based fuzzy decision system," IEEE Transactions on Energy Conversion, vol. 18, no. 4, pp. 469-475, December 2003.
[25] R. J. Romero-Troncoso, R. Saucedo-Gallaga, E. Cabal-Yepez, A. Garcia-Perez, R. A. Osornio-Rios, R. Alvarez-Salas, H. MirandaVidales, and N. Huber, "Fpga-based online detection of multiple combined faults in induction motors through information entropy and fuzzy inference," IEEE Transactions on Industrial Electronics, vol. 58, no. 11, pp. 5263-5270, 2011.

[26] M. S. Ballal, Z. J. Khan, H. M. Suryawanshi, and R. L. Sonolikar, "Adaptive neural fuzzy inference system for the detection of interturn insulation and bearing wear faults in induction motor," IEEE Transactions on Industrial Electronics, vol. 54, no. 1, pp. 250-258, 2007.

[27] S. Z. Gürbüz, Radar detection and identification of human signatures using moving platforms. PhD thesis, Georgia Institute of Technology, December 2009.

[28] S. M. Kay, Fundamentals of statistical signal processing, Volume II: Detection theory. Prentice Hall Upper Saddle River, NJ, USA:, January 1998.

[29] P. Stoica and Y. Selen, "Model-order selection: a review of information criterion rules," IEEE Transactions on Signal Processing Magazine, vol. 21, no. 4, pp. 36-47, July 2004.

[30] S. M. Kay, Fundamentals of Statistical Processing, Volume I: Estimation Theory. Upper Saddle River, Prentice Hall, Signal Processing, April 1993.

[31] D. G. Manolakis, V. K. Ingle, and S. M. Kogon, Statistical and Adaptive Signal Processing: Spectral Estimation, Signal Modeling, Adaptive Filtering, and Array Processing, vol. 46. Artech House Norwood, May 2005.

[32] P. Stoica and R. L. Moses, Spectral Analysis of Signals. Pearson/Prentice Hall Upper Saddle River, NJ, March 2005. 